Abstract 44 Table 2 Baseline characteristics of risers and nonrisers

\begin{tabular}{|c|c|c|c|}
\hline & $\begin{array}{l}\text { Riser pattern } \\
(\mathrm{N}=30)\end{array}$ & $\begin{array}{l}\text { Non-riser patterns } \\
\text { (dippers, extreme dippers } \\
\text { and non-dippers) } \\
(\mathrm{N}=216)\end{array}$ & $P$ value \\
\hline Age (years) & $72 \pm 7.68$ & $71.83 \pm 7.68$ & 0.909 \\
\hline LVEF -\% & $65 \pm 7.67 \%$ & $67.2 \pm 6.87 \%$ & 0.107 \\
\hline $\begin{array}{l}\text { Mean } 24 \text { hour systolic BP - } \\
\mathrm{mmHg}\end{array}$ & $133 \pm 11$ & $128 \pm 11$ & 0.016 \\
\hline $\begin{array}{l}\text { Mean daytime systolic BP - } \\
\mathrm{mmHg}\end{array}$ & $130 \pm 10$ & $132 \pm 12$ & 0.368 \\
\hline $\begin{array}{l}\text { Mean nocturnal systolic BP } \\
\text { - } \mathrm{mmHg}\end{array}$ & $138 \pm 13$ & $120 \pm 12$ & $<0.0001$ \\
\hline Female sex - No (\%) & $12 / 30(40 \%)$ & $81 / 216(37.5 \%)$ & 0.791 \\
\hline Diabetes mellitus - No (\%) & $8 / 30(26.7 \%)$ & $51 / 216(23.6 \%)$ & 0.713 \\
\hline $\begin{array}{l}\text { Coronary artery disease - } \\
\text { No }(\%)\end{array}$ & $13 / 30(43.3 \%)$ & $91 / 216(42.1 \%)$ & 0.900 \\
\hline Atrial fibrillation - No (\%) & $3 / 30(10 \%)$ & $21 / 216(9.72 \%)$ & 1.000 \\
\hline $\begin{array}{l}\text { Chronic kidney disease - } \\
\text { No (\%) }\end{array}$ & $2 / 30(6.67 \%)$ & $44 / 216(20.37 \%)$ & 0.082 \\
\hline ACE inhibitor use & $11 / 30(36.67 \%)$ & $85 / 216(39.35 \%)$ & 0.778 \\
\hline ARB use & $11 / 30(36.67 \%)$ & $87 / 216(40.28 \%)$ & 0.705 \\
\hline CCB use & $10 / 30(33.33 \%)$ & $97 / 216(44.91 \%)$ & 0.231 \\
\hline Thiazide use & $9 / 30(30 \%)$ & $64 / 216(29.63 \%)$ & 0.967 \\
\hline Loop diuretic use & $2 / 30(6.67 \%)$ & $10 / 216(4.63 \%)$ & 0.645 \\
\hline
\end{tabular}

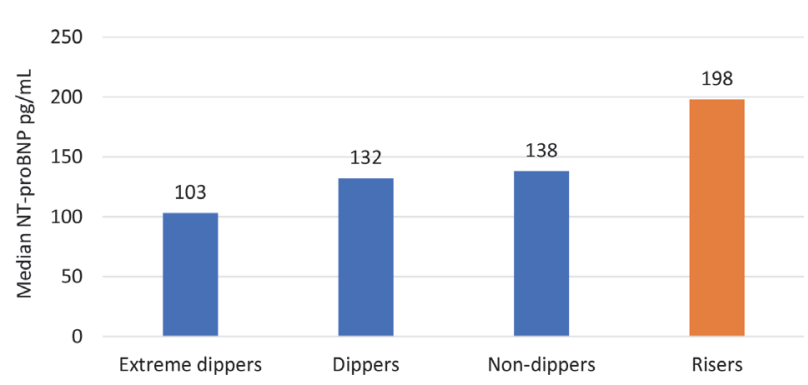

Abstract 44 Figure 1 NT-proBNP data across dipping groups

have higher daytime systolic BP $(137 \pm 10$ vs $125 \pm 10 \mathrm{mmHg}$; $\mathrm{p}<0.001)$ and rates of atrial fibrillation $(13.2 \%$ vs $4.9 \% ; \mathrm{p}=$ 0.031) compared to those with normal nocturnal BP, which could have confounded the analysis. There was a significant difference in median NT-proBNP across all dipping groups $(\mathrm{p}=0.043)$. Risers had the highest plasma NT-proBNP in comparison to other dipping groups combined:198pg/mL (IQR: 119-198) vs $135 \mathrm{pg} / \mathrm{mL}$ (IQR: 82.25-234.75) ( $\mathrm{p}=0.02)$. (See figure 1).

Conclusion Patients with NH had higher plasma NT-proBNP levels than those without nocturnal hypertension. Risers had the highest NT-proBNP data and therefore may be at increased risk of heart failure compared to other subgroups. This study provides evidence that nocturnal hypertension and abnormal dipping, pattern is associated with adverse cardiac physiological changes. This observation lends support for initiating the use of 24hour-ABPM to identify those with subclinical target organ damage for risk stratification and individualized treatment strategies.

\section{EVALUATING THE IMPACT OF COVID-19 ON REGIONAL PRIMARY PERCUTANEOUS CORONARY INTERVENTION SERVICE DURING THE FIRST WAVE OF COVID-19}

A Olusan, P Devlin, P Johnston. Belfast Royal Victoria Hospital, Belfast, UK

\subsection{6/heartjnl-2021-ICS.45}

Aims Primary Percutaneous Coronary Intervention (pPCI) remains the preferred reperfusion strategy for patients with ST-segment elevation myocardial infarction (STEMI). We evaluated the impact of first wave of COVID-19 on our pPCI service; was there a reduction in the number of pPCIs performed? Were referrals to the pPCI service inappropriately turned down?

Methods Retrospective observational study of all referrals to the Belfast pPCI service between 23rd March 2020 and 9th June 2020. All electrocardiograms (ECGs) were reviewed with corresponding referral history logged on a Microsoft Access

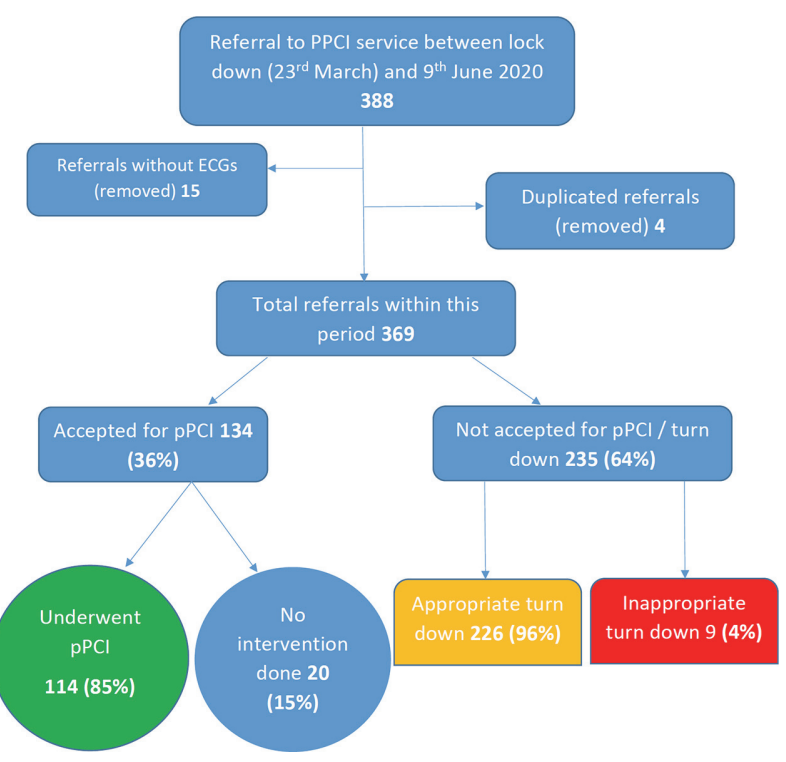

Abstract 45 Figure 1 Showing detail of all pPCI referrals received within the period of study

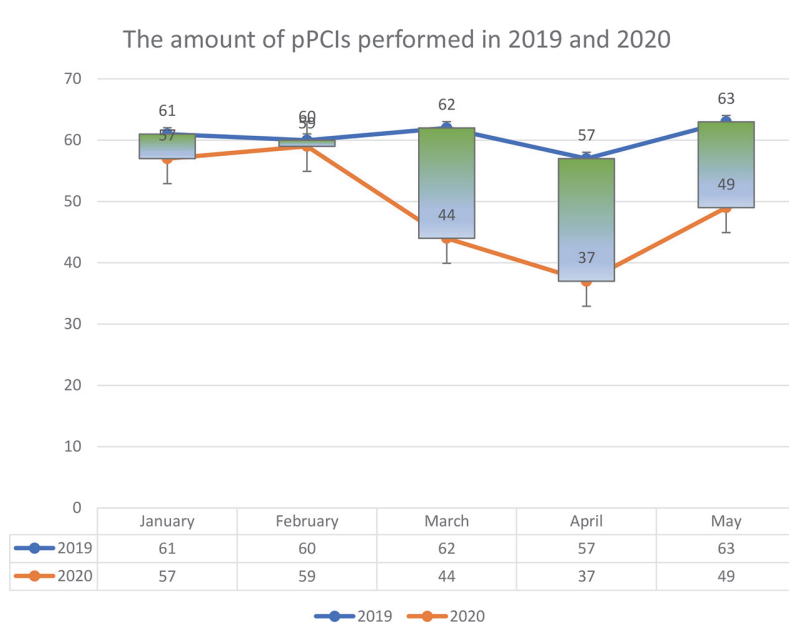

Abstract 45 Figure 2 Comparison between the numbers of $\mathrm{pPCls}$ performed between 2019 and 2020 
Abstract 45 Table 1 Showing baseline characteristics and source of patient referrals from the turned down cohort

\begin{tabular}{|c|c|}
\hline Characteristics & $\mathrm{n}=235(\%)$ \\
\hline Median Age (IQR) & $69(24,94)$ \\
\hline Male gender & $172(73)$ \\
\hline \multicolumn{2}{|l|}{ Referral source } \\
\hline Northern Ireland Ambulance Service (NIAS) & $146(62)$ \\
\hline Emergency Department & $68(29)$ \\
\hline In-patient & $21(9)$ \\
\hline \multicolumn{2}{|l|}{ Was the referral appropriately rejected? } \\
\hline No & $9(4)$ \\
\hline Yes & $226(96)$ \\
\hline $\mathrm{pPCl}$ done? & $224(95)$ \\
\hline No & $11(5)$ \\
\hline \multicolumn{2}{|l|}{ Yes } \\
\hline \multicolumn{2}{|l|}{ Patients re-referred for $\mathrm{PCl}$ ? } \\
\hline No & $182(77)$ \\
\hline Yes & $53(23)$ \\
\hline \multicolumn{2}{|l|}{ Number of patients who had intervention } \\
\hline $\mathrm{PCl}$ & $35(15)$ \\
\hline CABG & $2(1)$ \\
\hline Diabetes mellitus & $70(30)$ \\
\hline Hypertension & $133(57)$ \\
\hline Dyslipidaemia & $184(78)$ \\
\hline \multicolumn{2}{|l|}{ Smoking history } \\
\hline Never smoked & $73(31)$ \\
\hline Current smoker & $48(20)$ \\
\hline Ex-smoker & $86(37)$ \\
\hline Unknown & $28(12)$ \\
\hline Chronic kidney disease & $68(29)$ \\
\hline Prior ischaemic heart disease & $100(43)$ \\
\hline BMI (mean, SD) & $24.05 \pm 12.02 \mathrm{~kg} / \mathrm{m}^{2}$ \\
\hline Troponin T (median, IQR) & $35(0,10,000) \mathrm{ng} / \mathrm{L}$ \\
\hline Clinical COVID-19 diagnosis & $16(7)$ \\
\hline Covid-19 swab positive & $4(2)$ \\
\hline Mortality & $38(16)$ \\
\hline - Days before death (median, 1QR) & $10(0,157)$ \\
\hline
\end{tabular}

Abstract 45 Table 2 Showing the final diagnosis of patients and the proportion of patients who died during study period from the turned down cohort

\begin{tabular}{lll}
\hline Final Diagnosis & Number (\%) & Mortality (\%) \\
\hline STEMI & $12(5)$ & $2(5)$ \\
Late STEMI & $8(3)$ & $5(13)$ \\
NSTEMI & $41(17)$ & $4(11)$ \\
Unstable angina & $3(1)$ & 0 \\
Spontaneous coronary artery dissection & $1(0.5)$ & 0 \\
Angina & $13(6)$ & 0 \\
Takotsubo syndrome & $6(3)$ & $2(5)$ \\
Pericarditis & $3(1)$ & 0 \\
Myocarditis & $1(0.5)$ & 0 \\
Congestive cardiac failure & $10(4)$ & $3(8)$ \\
Arrhythmia & $29(12)$ & $5(13)$ \\
Non-cardiac chest pain & $25(11)$ & 0 \\
Miscellaneous & $67(29)$ & $12(32)$ \\
COVID & $16(7)$ & $5(13)$ \\
TOTAL & 235 & 38 \\
\hline
\end{tabular}

database and call log sheets. Supplementary clinical data was collected using the Northern Ireland Electronic Care Record (NIECR). A turn down was deemed inappropriate if retrospective review of history and ECG demonstrated that the pPCI pathway entry criteria had been met. The number of pPCIs performed was compared with the same time period in 2019. Results A total of 388 referrals were made to the Belfast pPCI service over a period of 78 days [figure 1]. 19 invalid referrals were excluded, 15 with missing ECGs and 4 duplicate referrals. 134 patients were accepted for pPCI and 235 referrals were turned down, of which 9 (4\%) were deemed inappropriate. No referrals were turned down due to COVID-19. Of the inappropriate turned downs 6 were re-referred and had pPCI to a culprit coronary artery, 2 had routine PCI to a culprit coronary artery and 1 had Takotsubo syndrome. From the accepted cohort, $114(85 \%)$ had pPCI to a culprit coronary artery and $20(15 \%)$ had no intervention (3 Takotsubo syndrome, 1 coronary spasm, 4 pericarditis, 3 chronic total occlusion of coronary artery, 8 non-obstructive coronary artery disease and 1 stroke). In the appropriately turned down cohort, the final diagnosis was cardiac in 127 (53\%) patients, non-cardiac chest pain in $25(11 \%)$, miscellaneous in 67 (29\%) and COVID-19 in 16 (7\%) [table 2]. One-year mortality rate of the turned down cohort was $16 \%$ (38/235) of which $55 \%(21 / 38)$ was in the cohort with a final cardiac diagnosis, $13 \%(5 / 38)$ was due to COVID-19 and the remaining $32 \%(12 / 38)$ from the miscellaneous cohort [table 1 and 2]. In 2020 there was a $29 \%$ (130 vs 182$)$ reduction in the number of pPCIs performed in the 3 months from March to May in comparison with the previous year [figure 2].

Conclusions During the first wave of COVID-19 there was a significant reduction in the number of pPCIs performed. This was not due to an increase in inappropriate turn down of referrals. No patient was turned down because of COVID-19. Of the turned down patients the majority (53\%) had a final cardiac diagnosis. One year mortality in this group was significant.

\section{ACUTE MYOCARDIAL INFARCTION AND LIPID LEVELS PRE AND POST PRIMARY \pm SECONDARY TREATMENT: A ONE-YEAR LIPID OUTCOME STUDY}

${ }^{1} \mathrm{M}$ Saad Ahmed, '1 Coburn, ${ }^{1} \mathrm{P}$ Collins, ${ }^{2}$ I Menown. ${ }^{1}$ Royal Victoria Hospital, Belfast Trust, NHS, UK; ${ }^{2}$ Craigavon Area Hospital, Southern Trust, NHS, UK

\subsection{6/heartjnl-2021-ICS.46}

ESC guidelines recommend a target LDL cholesterol (LDL-C) of $<1.8 \mathrm{mmol} / \mathrm{l}$ following myocardial infarction (MI). Early assessment of lipids post $\mathrm{MI}$ is confounded by acute phase response requiring convalescent re-testing to guide need or otherwise for up-titration \pm additional treatment.

Methods We studied consecutive patients admitted with acute myocardial infarction over one year (April 2016 - April 2017). Baseline diagnosis, cardiovascular (CV) risk factors, CV history, lipid treatment before admission (if any), lipid levels pre or within 24 hours of admission, lipid treatment on discharge, lipid levels at $>3$ months follow up, and changes to lipid treatment during follow up were recorded.

Results Of 293 patients admitted with acute MI, 108 (36.8\%) had ST elevation MI and 185(63.2\%) non-ST elevation MI or unstable angina. Gender split was approximately 2:1 male: female. Baseline CV risk factors included family history 63 